\title{
Growth of Carbonaceous Nanomaterials over Stainless Steel Foams. Effect of Activation Temperature.
}

\author{
N. Latorre ${ }^{1}$, F. Cazaña ${ }^{1}$, V. Sebastian ${ }^{1}$, C. Royo ${ }^{1}$, E. Romeo ${ }^{1}$, M.A. Centeno ${ }^{2}$ and A. Monzón ${ }^{1 *}$ \\ ${ }^{1}$ Departamento de Ingeniería Química y Tecnologías del Medio Ambiente, Instituto de Nanociencia de \\ Aragon (INA), Universidad de Zaragoza, 50009 Zaragoza, Spain. (*) email: amonzon@unizar.es \\ ${ }^{2}$ Instituto de Ciencia de Materiales de Sevilla (CSIC-Universidad de Sevilla), Sevilla, Spain.
}

\begin{abstract}
Some of the problems that occur during the operation of chemical reactors based of structured catalytic substrates, as monoliths, foams, membranes, cloths, fibres and other systems, are related to the preparation of long term stable coatings. Frequently, the deposition of the catalytic layer is carried out by washcoating, requiring this step a cautious attention, especially in the case of complex geometries, like of that of foams or cloths. In the case of the deposition of layers of carbonaceous materials (CNMs), an alternative route, avoiding the washcoating, it is their direct growth by catalytic decomposition light hydrocarbons (also called CCVD), over the surface of the metallic substrate. In this case, if the metallic substrate is of stainless steel, it already contains the catalytic active phases like Fe and $\mathrm{Ni}$.

In order to optimize the process of CNMs growth over structured metallic substrates, we are studying the effect of the main operational variables of the ethane decomposition reaction on stainless steel foams. In this contribution we present a study of the influence of the temperature of the activation (oxidation and reduction) stage on the type and morphology of the carbonaceous materials formed. The results obtained allow us to determine the optimal operating conditions to maximize the amount and the selectivity of the process to obtain a given type of CNM.
\end{abstract}

\section{Keywords}

Stainless steel foam, metallic washcoating, CCVD, carbon nanofibers, graphene. 


\section{Introduction.}

The potential possibilities of application of the outstanding properties of carbonaceous nanomaterials (CNMs), like carbon nanotubes (CNTs), carbon nanofibers (CNFs) or graphene, have motivated the huge research effort carried out during the last twenty five years in practically all fields of nanoscience and nanotechnology [1-3]. These carbonaceous nanomaterials are compounds with unique mechanical, electronic, chemical and physical properties [4-6].

Among the different technologies used, catalytic chemical vapour deposition (CCVD) has become the main technique for the synthesis of CNMs, due to its easiness of scale-up, reducing significantly the costs of production [7]. During the CCVD process of decomposition of light hydrocarbons over the surface of the metallic nanoparticles (e.g. Ni, Co, Fe) dispersed on a high surface area carrier, the CNMs are obtained in a powdered form $[2,8]$, which is a major drawback in many applications as for example, as catalytic supports in structured reactors.

The structured catalytic substrates, as monoliths, foams, membranes, cloths, fibres and other systems, due to their flexibility, have been applied to two- and threephase reactions, showing substantial improvements of mass and heat transfer, pressure drop and productivity [9-10]. However, these systems present problems related to the preparation of long term stable coatings [9-10]. Frequently, the deposition of the catalytic layer over the surface of metallic substrate is carried out by means of a washcoating stage, requiring this step a cautious attention, especially in the case of complex geometries, like of that of foams or cloths [11-16].

In the case of the deposition of layers of carbonaceous materials, an alternative route, that avoids the washcoating, it is their direct synthesis over the surface of the metallic substrate, e.g. stainless steel (SS), taking advantage of the stainless steel contains some of the active components, like $\mathrm{Fe}$ and $\mathrm{Ni}$, that are able to catalyse the hydrocarbon decomposition [17-24].

The hybrid system formed by CNMs grown over monoliths, foams or meshes has been used as filters, adsorbents, sensors, reinforcements of polymers or composites for enhanced heat transfer. [28-32]. For example, the CNFs grown by CCVD on the surface of SS foam boost the heat transfer efficiency from $30 \%$ to $75 \%$, due to the enlargement of the surface area provided by the CNFs. Therefore, the combination of 
metallic filters with CNFs coatings results in composites with a high thermal conductivity [33].

Recently, Reichelt et al. have studied the use of this type of devices as catalytic reactors in several reactions [9]. In an example of their application during the reaction of ozone oxidation using SS meshes [20], the electrodeposition of Co nanoparticles over the surface of MWCNT, previously grown on the SS, increases notoriously the kinetic constant of the reaction. This fact was due to the higher dispersion attained by the Co particles, compared with the case of deposition over the bare mesh [20]. In the same framework, recently we have developed a study of the selective oxidation of $\mathrm{CO}$ in the presence of $\mathrm{H}_{2}$, using Pt nanoparticles deposited over CNFs. The CNFs was directly grown, by catalytic decomposition of ethanol, over the inner surface of the channels of microreactors, made of stainless steel [34]. The results obtained with the $\mathrm{Pt} / \mathrm{CNF} /$ microreactor system clearly outperformed those obtained with a typical fixed bed configuration, operated at the same space velocity, attaining total $\mathrm{CO}$ conversion at lower temperatures $\left(\mathrm{ca} .50^{\circ} \mathrm{C}\right)$.

With the aim of developing these devices in order to be used in new applications, our main goal is the optimization of the CNMs growth process over structured metallic substrates. With this goal, we are studying the kinetics of growth of carbonaceous nanomaterials during the reaction of ethane decomposition over foams of stainless steel. In this contribution we present a study of the influence of the temperature of the activation stage on the type and morphology of the carbonaceous materials formed. The activation of the fresh foam was made carrying out consecutive treatments of oxidation and reduction at high temperature. The foam and the CMNs obtained have been characterized, before and after reaction, to know the changes on the foam structure, and also the type and characteristics of the carbonaceous nanomaterials formed. The results obtained allow us to determine the optimal operating conditions to maximize the amount and the selectivity of the process to de desired type of CNMS.

\section{Material and methods.}

The stainless steel foam used (AISI 316L) was supplied by Goodfellow ${ }^{\circledR}$ (www.goodfellow.com, ref: FE243825). The foam is a rigid three-dimensional structure with large pores that allows the feed stream easily flow with low pressure drop, and 
showing large superficial surface. The main characteristics are: thickness: $6.35 \mathrm{~mm}$; density: $0.55 \mathrm{~g} . \mathrm{cm}^{-3}$; porosity: $93 \%$; pores $/ \mathrm{cm}$ : 24 . The foam was cut in $10 \mathrm{~mm}$ x10 mm pieces to be placed inside the reactor.

The bulk chemical composition of the foam was measured by atomic absorption in a VARIAN spectrophotometer (model SPECTRAA 110). In Table 1 is presented the bulk composition, determined by atomic absorption (AA) of the foam. As mentioned above, the presence of large amounts of Fe (ca. $70 \%$ ) and $\mathrm{Ni}$ (ca. $10 \%$ ) allows to the foam be used as a suitable catalyst to carry out the reaction of ethane decomposition [35-40].

After reaction, the foam as the carbonaceous materials obtained were characterized by transmission and scanning electron microscopy, X-ray diffraction, Raman spectroscopy and Energy dispersive X-ray spectroscopy (SEM-EDX).

TEM images were recorded in a FEI Tecnai T-20 microscope, operated at 200 $\mathrm{kV}$. Scanning electron microscopy (SEM) micrographs images were captured in a FEI Inspect F50 microscope, operated at $10 \mathrm{kV}$. This microscope was also used to measure the weight ratio of the components in the surface of the stainless steel foam with an energy dispersive X-ray (EDX). The X-ray diffraction (XRD) patterns were recorded within the range of $10-90^{\circ}(2 \theta)$, in a Rigaku/Max $\mathrm{Cu}$ rotatory anode equipment, operating at $40 \mathrm{kV}$ and $80 \mathrm{~mA}$ using $\mathrm{Cu} \mathrm{K}_{\alpha}$ radiation. Raman spectra were taken using the $532 \mathrm{~nm}$ laser excitation beam on a WiTec Alpha300 Confocal Raman Microscope.

The adherence of the carbon coatings was evaluated using a method described by Yasaki et al. [41] that is based in the measurement of the weight loss caused by exposure to ultrasound. This method was also applied by Valentini et al. [42] for alumina layers on ceramic and metallic monolithic supports to comparatively measure changes in the washcoating adherence when silica was used as a binder. Boix et al. [43] also used the method for PtCoFerrierite-washcoated cordierite monoliths. The coated foam was immersed in water inside a Pyrex vessel and then kept in an ultrasound bath at $50^{\circ} \mathrm{C}$ for $1 \mathrm{~h}$. After that, the sample was dried during $24 \mathrm{~h}$ at $393 \mathrm{~K}$. The weight of the sample was measured after and before the ultrasonic treatment.

Ethane decomposition reaction was carried out in gas phase at $800{ }^{\circ} \mathrm{C}$ and at atmospheric pressure, using a thermobalance (CI Electronics Ltd., UK, model MK2) as differential reactor. The experimental set-up, equipped with mass-flow and temperature 
controllers, allows the continuous recording of mass and temperature variations along all the stages: oxidation, reduction and reaction, see Figure 1. Previous to the reaction of ethane decomposition, the metallic foam is oxidized and reduced in-situ (activation steps). The reaction was carried out feeding $600 \mathrm{NmL} / \mathrm{min}$ of a mixture of $1.67 \% \mathrm{H}_{2} / 33.33 \% \mathrm{C}_{2} \mathrm{H}_{6} / 65 \% \mathrm{~N}_{2}$. The operating conditions used during activation stages were: i) Oxidation: Temperature: from 700 to $900{ }^{\circ} \mathrm{C}$; time: $60 \mathrm{~min}$ at final temperature (heating rate: $10{ }^{\circ} \mathrm{C} / \mathrm{min}$ ); mass flowrate: $200 \mathrm{NmL} / \mathrm{min}$; feed composition: $50 \%$ air $/ 50 \% \mathrm{~N}_{2}$; ii) Reduction: Temperature: from 700 to $900{ }^{\circ} \mathrm{C}$; mass flowrate: 200 $\mathrm{NmL} / \mathrm{min}$; feed composition: $50 \% \mathrm{H}_{2} / 50 \% \mathrm{~N}_{2}$.

\section{Results and discussion.}

Figure 1 shows the variations of the weight of the sample along the successive stages (oxidation, reduction and reaction) of a typical experiment. The temperatures used in this case for the oxidation, reduction and reaction steps were $800{ }^{\circ} \mathrm{C}$. As was expected, the weight of the sample increases and then diminishes along oxidation and reduction steps. After the reduction the catalytically active phases are generated and segregated on the external surface of the foam. However, typically it is observed that after the reduction, the weight does not decrease till the initial level, indicating that the total amount of oxides formed in the oxidation stage is not reduced.

Figure 2 shows the SEM images of the fresh foam (a), after oxidation (b) and (c) and after reduction (d). Before any thermal treatment, the surface of the foam is quite smooth (Fig. 2.a). The oxidation process generates a layer of oxide (Figure 1), modifying the external surface of the foam, creating fractures (Figure 2.b and 2.c), and, in consequence, increasing the external surface area [20].

Figure 3 includes the XRD patterns of the foam after each step. The diffractogram of the fresh AISI316L stainless steel material shows the characteristic peaks of the austenite (JCPDS 33-397) and martensite (JPCDS 44-1290) phases. After oxidation at $800{ }^{\circ} \mathrm{C}$, an oxide layer, formed mainly by $\left(\mathrm{Fe}_{0.6} \mathrm{Cr}_{0.4}\right)_{2} \mathrm{O}_{3}$, (JCPDS 034-412), is generated on the surface [44]. After the reduction treatment, the coating layer of oxide disappears and the XRD pattern is almost coincident with that of the fresh foam.

The relative content of the elements present at the surface after the reduction, were analysed by energy dispersive X-ray (EDX) technique. One representative 
example of the EDX spectrum obtained for the sample oxidized and reduced at $800^{\circ} \mathrm{C}$ is shown in Figure 4, where oxygen, carbon and the main metallic components were detected. The results of composition are included in Table 1, and comparing these values with the bulk composition is observed an enrichment of the surface on Fe (from 70 to $76 \%$ ), while the $\mathrm{Ni}$ content decreases from 10 to $5 \%$. The high content and availability of $\mathrm{Fe}$ and $\mathrm{Ni}$ at the surface explains the activity showed by the stainless steel foam during the ethane decomposition reaction.

The XRD patterns after reaction (Figure 3.d) shows, besides those signals corresponding to the bare foam, an intense diffraction characteristics of very crystalline graphite $2 \mathrm{H}$ (JCPDS 41-1487) and several ones ascribed to metal carbides, like $\mathrm{Fe}_{3} \mathrm{Mo}_{3} \mathrm{C}$ (JCPDS 47-1191), and $\mathrm{Fe}_{3} \mathrm{C}$ (JCPDS 01-077-0255). The presence of these carbides corroborates the usually accepted mechanism of carbon nanotubes formation. According this mechanism, after the adsorption and decomposition of the hydrocarbon molecules at the surface of the reduced metallic particles, it is formed a layer of a metaestable carbide [22, 45-47]. The decomposition of this surface carbide leaves carbon atoms inside the metallic particles, which migrate by diffusion through them, and finally precipitate, at the rear side of the nanoparticles. This process leads to the formation of carbonaceous nanomaterials like carbon nanotubes, carbon nanofibers or even graphene, causing the increase of the weight of the sample along the reaction. (Figure 1).

\section{Influence of the oxidation temperature.}

In Table 2 are summarized the variations of weight suffered by the sample after the steps of oxidation, reduction and reaction (see also Figure 1). As expected, the rise of the oxidation temperature increases the amount of foam oxidized $\left(\Delta W_{\text {oxid. }} / W_{0}\right)$ and also quantity of oxide reduced in the subsequent stage $\left(\Delta W_{\text {reduc. }} / W_{0}\right)$. An increase in the oxidation temperature intensifies in the kinetics of foam oxidation, generating more metallic oxide and, in consequence, allowing in the next step more reduction (i.e. more active metal available). Regarding the fraction of oxide reduced ( $\left.\Delta W_{\text {reduc. }} / W_{\text {oxid. }}\right)$, it was obtained that the amount reduced represents around the half $\left(56 \%\right.$ at $700{ }^{\circ} \mathrm{C}$, and $46 \%$ at $900{ }^{\circ} \mathrm{C}$ ) of the amount of oxide generated. Therefore, in addition to the unreduced parts Fe and Ni oxides, some of the oxides formed, e.g chromium oxide, are quite less reducible that those of $\mathrm{Ni}$ and $\mathrm{Fe}$. 
In addition, in Figure 5 is presented the evolution of carbon content deposited during the decomposition of ethane on samples oxidized at 700,800 and $900{ }^{\circ} \mathrm{C}$. The curves show the increase along time of the mass, due to the accumulation of carbonaceous nanomaterials on the surface of the foam. The total amount of carbon generated increases with the oxidation temperature because, as it is shown in Table 2, the quantity of active sites available for the hydrocarbon decomposition is higher as the oxidation temperature increases. Nevertheless, the pattern of growth of these curves is different. Thus, for the sample oxidized at low temperatures $\left(\right.$ e.g. $\left.700{ }^{\circ} \mathrm{C}\right)$, the curve of Cc vs. time is clearly sigmoidal, indicating that during the reaction time the steps of carburization, diffusion and precipitation of the mechanism of carbon formation are completed [22, 25, 39, 40, 45-48]. However, after oxidation at 800 and especially at 900 ${ }^{\circ} \mathrm{C}$, the curves are in the initial period of the sigmoidal behaviour, because the early stages of the carbon nanomaterials formation are still in development. This fact can be originated by the large size of the metallic nanoparticles of Fe-Ni obtained after oxidation at $900{ }^{\circ} \mathrm{C}$, cause a delay on the carbon atoms diffusion, at therefore on the precipitation of the carbon to form carbon nanofibers [49]. Nevertheless, the larger amount of carbon obtained after oxidation at $900{ }^{\circ} \mathrm{C}$, it is explained by the higher amount of Ni-Fe nanoparticles generated, as it has been discussed previously (Table 2).

Concerning the type of the nanomaterials formed, SEM micrographs presented in Figure 6 show the formation of a layer of entangled nanofibers after oxidation temperature at $800^{\circ} \mathrm{C}$. However, after oxidation at $900{ }^{\circ} \mathrm{C}$, the filaments appear to be thicker and shorter, and also there is non-filamentous carbon. This information is complemented with TEM and Raman measurements. TEM micrographs, Figure 7, show the formation of carbon nanofibers with bamboo-like structure. In some cases, it can be seen the presence of metallic nanoparticles in the inner part of the carbon nanofibers, which have been trapped during the growth of the CNFs. The large diameter of these CNFs, around $30-40 \mathrm{~nm}$, is consequence of the elevated temperature used during the activation, triggering the sintering of the metallic particles. For the sample oxidized at $900^{\circ} \mathrm{C}$, TEM images (Figure 7.c-d) also show formation of carbon nanofibers with bamboo-like structure. However, in this case is also found graphite (see Figure 8.a), encapsulating the metallic nanoparticles. More interestingly, in Figure 8, it can be also observed that the external surface of the graphite layer is being exfoliated to form unstructured carbonaceous flakes (Figure 8.a), which can later evolve to form graphene 
and materials like the so-called "few layer graphene-FLG" (Figure 8.b-d) [50-53]. Therefore, in agreement with the kinetics results presented in Figure 5, in these operating conditions, the carbon growth pass through an initial step of nucleation of a thin layer of coating graphite, and a subsequent step of exfoliation of this coat of graphite, leaving separate layers of graphene and FLG [54].

Figures 9 and 10 show the Raman spectra of the samples after reaction with foams calcined at $800{ }^{\circ} \mathrm{C}$ and $900{ }^{\circ} \mathrm{C}$ respectively. In each figure are presented three spectra corresponding to three different points of the same sample. In the case of the sample calcined at $800{ }^{\circ} \mathrm{C}$ the Raman spectra corresponds to a similar type of carbon, with values of the $\mathrm{I}_{2 \mathrm{D}} / \mathrm{I}_{\mathrm{G}}$ ratio around $0.4(0.37-0.56)$ and of $\mathrm{I}_{\mathrm{G}} / \mathrm{I}_{\mathrm{D}}$ ratio in the interval 1.97-2.49. These values are in accordance with the presence of CNFs observed by SEM and TEM, see Figures 6 and 7 [55-56].

For the sample oxidized at $900{ }^{\circ} \mathrm{C}$ the Raman spectra corresponds to a heterogeneous sample where there are $\mathrm{CNFs}\left(\mathrm{I}_{2 \mathrm{D}} / \mathrm{I}_{\mathrm{G}}=0.4, \mathrm{I}_{\mathrm{G}} / \mathrm{I}_{\mathrm{D}}=2.22\right)$, see Figure 10.c; graphite $\left(\mathrm{I}_{2 \mathrm{D}} / \mathrm{I}_{\mathrm{G}}=1.39\right.$ and $\left.\mathrm{I}_{\mathrm{G}} / \mathrm{I}_{\mathrm{D}}=0.6\right)$, see Figure 10.b, and FLG (2D peak at $\sim 2675 \mathrm{~cm}^{-1}$, $\left.\mathrm{I}_{2 \mathrm{D}} / \mathrm{I}_{\mathrm{G}}=0.77, \mathrm{I}_{\mathrm{G}} / \mathrm{I}_{\mathrm{D}}=2.85\right)$, Figure 10.a. Although the intensity of the $\mathrm{D}$ band $\left(\sim 1350 \mathrm{~cm}^{-}\right.$ ${ }^{1}$ ) is too large to be attributed to graphite, considering that the resolution of the equipment used is $1 \mu \mathrm{m}$, this peak can be influenced by the presence of CNFs, modifying the spectra. Therefore, selecting the operating conditions of the CCVD process, it is possible to obtain materials like graphene and FLG using metallic substrates of stainless steel.

\section{Influence of the reduction temperature.}

As in the previous case, in Table 3 are presented the variations of weight suffered by the sample after all the steps of process. Regarding the oxidation step, first column, it can be seen that the weight increased during the oxidation, i.e. the quantity of superficial oxide formed, $\Delta W_{\text {oxid. }} / W_{0}$, is almost the same in all the experiments, indicating a good reproducibility of the experimental procedure used. On the other side, the total $\left(\Delta W_{\text {reduc. }} / W_{0}\right)$ and relative $\left(\Delta W_{\text {reduc. }} / W_{\text {oxid. }}\right)$ amount of reduced oxide passes through a maximum at ca. $800{ }^{\circ} \mathrm{C}$. At this temperature of reduction, the amount of oxide reduced is almost twice $(1.9 / 1)$ that at $900{ }^{\circ} \mathrm{C}$. The existence of this maximum can be explained considering that the increase of the reduction temperature, not only enhances the rate of reduction, but also the sintering rate of the metallic particles that are being 
produced in this step. The reduction of the metallic particles is a gas-solid reaction, and therefore the formation of large particles hinders this phenomenon. The final consequence is that the number of active sites (directly related with the number of atoms of $\mathrm{Fe}$ an $\mathrm{Ni}$ exposed) at the gas side of the foam surface, decreases causing a loss of activity for the ethane decomposition reaction. In addition, the formation of nonreducible compounds also explain the low values obtained for the ratio $\Delta W_{\text {reduc. }} / W_{\text {oxid. }}$.

Figure 11 shows the effect of reduction temperature on the evolution of the carbon content during the reaction. As indicate the data presented in Table 3 , there is a maximum on carbon productivity at $800{ }^{\circ} \mathrm{C}$, as consequence of the balance between the opposite effects of reduction and sintering phenomena that suffer the metallic nanoparticles. In addition, the evolution of these curves indicate that the catalytic nanoparticles of $\mathrm{Fe}-\mathrm{Ni}$ does not deactivate, and maintains the productivity along the experiment [47-48].

On the other side, SEM and TEM results after reaction, of the foam reduced at $900{ }^{\circ} \mathrm{C}$ (not shown here) show the formations of bamboo-like CNFs. In addition, the Raman spectra presented in Figure 12, corresponding to 3 different points of the same sample, indicate that, in this case, type of carbon formed is quite similar along the surface of the foam. The values of the $\mathrm{I}_{2 \mathrm{D}} / \mathrm{I}_{\mathrm{G}}$ ratio are around $0.5(0.41-0.55)$ and of $\mathrm{I}_{\mathrm{G}} / \mathrm{I}_{\mathrm{D}}$ ratio in the interval 1.67-2.35, match with the preponderance of CNFs.

In summary, the most favourable temperature of activation of the stainless steel foam used is $800^{\circ} \mathrm{C}$. At this temperature, the activity of the foam is high enough; see Figures 5 and 11, yielding an average productivity of around $17 \mathrm{mg} \mathrm{C} / \mathrm{g}$ foam.min. Moreover, the bamboo-like CNFs formed on the surface of the foam in these conditions are materials quite appropriated to be used as catalytic support [57].

Under practical conditions, structured catalytic reactors should be able to operate at broad ranges of flowrates (gas or liquids), during long reaction times. The potential damage of the CNMs adherence could be a major drawback because the loss of the catalytic washcoat causes an irreversible reduction of reactor productivity. In order to check the adherence of the carbonaceous nanomaterials formed during the reaction, we performed some tests using a method described by Yasaki et al. [41]. Briefly, during the adherence tests the coated foam were immersed in water inside a Pyrex vessel and then kept in an ultrasound bath at $50^{\circ} \mathrm{C}$ for $1 \mathrm{~h}$. After that, the sample was dried during $24 \mathrm{~h}$ at $393 \mathrm{~K}$. After the tests was registered a loss of weight of around $15 \%$ of the coating 
material, for the samples after oxidation, reduction and reaction at 700 and $800{ }^{\circ} \mathrm{C}$. In the rest of the cases the losses were higher. Furthermore, the use of the same temperature in all the stages simplifies the integration of the process at industrial level, minimizing the potential thermal fatigue that can suffer of the foam.

Finally, in this point it is interesting to note that, the results confirm that stainless steel is an adequate substrate to produce, by CCVD, valuable materials like graphene and FLG, with extraordinary electronic and mechanical properties [58].

\section{Conclusions.}

The results obtained in this study demonstrate that it is possible to use stainless steel substrates, like foams, to homogeneously produce layers of carbonaceous nanomaterials, like carbon nanofibers, by catalytic decomposition of light hydrocarbons. However, selecting the operating conditions of the CCVD process, it is also possible to obtain other materials like graphene and FLG. In particular, in the present case the use of high temperatures of oxidation in the activation stage, leads to the formation of these valuable materials with extraordinary electronic and mechanical properties.

In any case, from the point of view of the development of a suitable catalytic reactor the most favourable temperature of activation of the stainless steel foam is $800^{\circ} \mathrm{C}$. At this temperature, the productivity of the foam is high enough, $17 \mathrm{mg} \mathrm{C} / \mathrm{g}$ foam.min, and the type of CNM formed are CNFs that are very suitable to be used as catalytic support.

The activity of the foam presents a maximum for a temperature of reduction of $800{ }^{\circ} \mathrm{C}$. The operation at higher temperatures increases the rate of the opposite phenomena: the reduction (increasing the activity), and the sintering (decreasing the activity) of the metallic particles. The balance between both processes explains the presence of a maximum productivity of the foam.

Finally, the adherence tests indicate that the optimal conditions of the CCVD process are found after oxidation, reduction and reaction at $800^{\circ} \mathrm{C}$. In this way, the integration of the process at industrial level, and also, the potential thermal fatigue that can suffer of the foam is minimized. 


\section{Acknowledgements.}

The authors acknowledge financial support from MINECO (Madrid, Spain) FEDER, Project ENE2013-47880-C3-1-R

\section{References.}

[1] M.S. Dresselhaus, G. Dresselhaus, Ph. Avouris (Eds.), Carbon Nanotubes: Synthesis, Structure, Properties and Applications, Springer-Verlag, Berlin, 2001.

[2] K.P. De Jong, J.W. Geus, Catal. Rev. Sci. Eng. 42 (2000) 481-510.

[3] P. Serp, M. Corrias, P. Kalk, Appl. Catal. A 253 (2003) 337-358.

[4] A. Chatterjee, B.L. Deopura, Fiber Polym. 3 (2002) 134-139.

[5] M. Inagaki, L.R. Radovic, Carbon 40 (2002) 2279-2282.

[6] M. Terrones, Annu. Rev. Mater. Res. 33 (2003) 419-501.

[7] C.E. Baddour, C. Briens, Carbon Nanotube Synthesis: A Review, in: H. Lasa, C.C. Xu (Eds.), International Journal of Chemical Reactor Engineering: Vol. 3: R3 (2005).

[8] K.B.K. Teo, C. Singh, M. Chhowalla, W.I. Milne, Catalytic synthesis of carbon nanotubes and nanofibres, in: H.S. Nalwa, editor, Encyclopedia of nanoscience and nanotechnology, vol. 10, American Scientific Publishers, 2003. pp. 1-22.

[9] E. Reichelt, M.P. Heddrich, M. Jahn, A. Michaelis, Appl. Catal. A 476 (2014) 7890.

[10] Y. Matatov-Meytal, M. Sheintuch, Appl. Catal. A, 231 (2002) 1-16.

[11] F. Kokai, I. Nozaki, T. Okada, A. Koshio, T. Kuzumaki, Carbon 49(4) (2011) $1173-1181$.

[12] S. Noda, H. Sugime, K. Hasegawa, K. Kakehi, Y. Shiratori, Japanese Journal of Applied Physics 49(2) (2010) 02BA02.

[13] J. Amadou, D. Begin, P. Nguyen, J.P. Tessonnier, T. Dintzer, E. Vanhaecke, M.J. Ledoux, C. Pham-Huu, Carbon 44(12) (2006) 2587-2592.

[14] T. Kato, R. Hatakeyama, ACS Nano. 4(12) (2010) 7395-7400. 
[15] S. Maruyama, R. Kojima, Y. Miyauchi, S. Chiashi, M. Kohno, Chem. Phys. Lett. 360(3-4) (2002) 229-234.

[16] K. Hata, D.N. Futaba, K. Mizuno, T. Namai, M. Yumura, S. Iijima, Science 306(5700) (2004) 1362-1364.

[17] C.E. Baddour, F. Fadlallah, D. Nasuhoglu, R. Mitra, L. Vandsburger, J.L. Meunier, Carbon 47(1) (2009) 313-318.

[18] C.E. Baddour, D.C. Upham, J.L. Meunier, Carbon 48(9) (2010) 2652-2656.

[19] S. Pacheco Benito, L. Lefferts, Carbon 48 (2010) 2862-2872.

[20] N. Sano, Y. Hori, S. Yamamoto, H. Tamon, Carbon 50 (2012) 115-122.

[21] N. Sano, S. Yamamoto, H. Tamon, Carbon 50 (2012) 5618-5630.

[22] N. A. Jarrah, J.G. van Ommen, L. Lefferts, Journal of Catalysis 239 (2006) 460469.

[23] L.Z. Gao, L. Kiwi-Minsker, A. Renken, Surface \& Coatings Technology 202 (2008) 3029-3042.

[24] P. Tribolet, L. Kiwi-Minsker, Catalysis Today 102-103 (2005) 15-22.

[25] V. Martínez-Hansen, N. Latorre, C. Royo, E. Romeo, E. García-Bordejé, A. Monzón, Catalysis Today 147S (2009) S71-S75.

[26] M. V. Twing, D. E.Webster, Metal and Coated Metal Catalysts, in: A. Cybulski, J.A. Moulijn (Eds.), Structured Catalysis and Reactors ( $2^{\text {nd }}$ Ed.), CRC Press, Boca Raton, FL, USA, 2006, Chapter 3.

[27] G. Ertl, H. Knözinger, J.Weitkamp, Environmental Catalysis, Wiley-VCH, Weinheim, 1999.

[28] N.M. de Almeida Coelho, J.L.B. Furtado, C. Pham-Huu, R. Vieira, Mater. Res. 11(3) (2008) 353-357.

[29] C. Pham-Huu, M.J. Ledoux, Top. Catal. 40(1-4) (2006) 49-63.

[30] R.L. Vander Wal, L.J. Hall, Adv. Eng. Mater. 6(1) (2004) 48-52.

[31] Y. Yun, R. Gollapudil, V. Shanov, M.J. Schulz, Z. Dong, A. Jazieh, W.R. Heineman, H.B. Halsall, D.K. Wong, A. Bange, Y. Tu, S. Subramaniam, Journal of Nanoscience and Nanotechnology 7(3) (2007) 891-897. 
[32] C.R. Dietz, Y.K. Joshi, Nanoscale Microscale Thermophys. Eng. 12(3) (2008) $251-271$.

[33] I. Tuzovskaya, S. Pacheco Benito, J.K. Chinthaginjala, C. Reed, L. Lefferts, T. van der Meer, International Journal of Heat and Mass Transfer 55 (2012) 57695776.

[34] A. Ramírez, V. Sebastián, R. Mallada, J. Santamaría, A. Monzón, Appl. Catal. A 505 (2015) 193-199.

[35] T. Zhang, M.D. Amiridis, Appl. Catal. A 167 (1998) 161-172.

[36] G.G. Kuvshinov, Yu.I. Mogilnykh, D.G. Kuvshinov, V.I. Zaikovskii, L.B. Avdeeva, Carbon 36 (1998) 87-97.

[37] S.B. Sinnott, R. Andrews, D. Qian, A.M. Rao, Z. Mao, E.C. Dickey, F. Derbyshire, Chem. Phys. Lett. 315 (1999) 25-30.

[38] R. Aiello, J.E. Fiscus, H.C. Loye, M.D. Amiridis, Appl. Catal. A 192 (2000) 227234.

[39] P. Benito, M. Herrero, F.M. Labajos, V. Rives, C. Royo, N. Latorre, A. Monzón, Chemical Engineering Journal 149 (2009) 455-462

[40] N. Latorre, F. Cazaña, V. Martínez-Hansen, C. Royo, E. Romeo, A. Monzón, Catalysis Today 172 (2011) 143-151.

[41] S. Yasaki, Y. Yoshino, K. Ihara, K. Ohkubo, U.S. Patent No. 5,208,206 (4 May 1993).

[42] M. Valentini, G. Groppi, C. Cristiani, M. Levi, E. Tronconi, P. Forzatti, Catalysis Today 69 (2001) 307-314.

[43] A.V. Boix, J.M. Zamaro, E.A. Lombardo, E.E. Miró, Applied Catalysis B 46 (2003) 121-132.

[44] A. Bautista, F. Velasco, M. Campos, M. E. Rabanal, J. M.Torralba, Oxidation of Metals 59 (2003) 373-393.

[45] I. Alstrup, J. Catal. 109 (1988) 241-251.

[46] J.W. Snoeck, G.F. Froment, M. Fowles, J. Catal. 169 (1997) 240-249. 
[47] N. Latorre, E. Romeo, F. Cazaña, T. Ubieto, C. Royo, J. I. Villacampa, A. Monzón, J. Phys. Chem. C, 114 (2010) 4773-4782.

[48] N. Latorre, E. Romeo, J.I. Villacampa, F. Cazaña, C. Royo, A. Monzón, Catal. Today 154 (2010) $217-223$.

[49] D. Chen, K.O. Christensen, E. Ochoa-Fernandez, Z. Yu, B. Tøtdal, N. Latorre, A. Monzón, A. Holmen, J. Catal, 229 (1) (2005) 82-96.

[50] A.C. Ferrari, J.C. Meyer, V. Scardaci, C. Casiraghi, M. Lazzeri, F. Mauri, S. Piscanec, D. Jiang, K.S. Novoselov, S. Roth, A.K. Geim, Phys. Rev. Lett. 97 (2006) 187401.

[51] D. Graf, F. Molitor, K. Ensslin, C. Stampfer, A. Jungen, C. Hierold, L. Wirtz, Nano Lett. 7 (2007) 238-242.

[52] C. Faugeras, A. Nerriere, M. Potemski, A. Mahmood, E. Dujardin, C. Berger, W.A. de Heer, Appl. Phys. Lett. 92 (2008) 011914.

[53] A.K. Geim, Science 324 (2009) 1530-1534.

[54] J.C.W. Swart, E. van Steen, I. M. Ciobícă, R. A. van Santen, Physical Chemistry Chemical Physics 11 (2009) 803-807.

[55] S. Takenaka, S. Kobayashi, H. Ogihara, K. Otsuka, Journal of Catalysis, 217 (2003) 79-87.

[56] G. Zhanga, S. Sunb, D. Yanga, J.P. Dodeletb, E. Sachera, Carbon, 46 (2008) 196205.

[57] L.M. Malard, M.A. Pimenta, G. Dresselhaus, M.S. Dresselhaus, Physics Reports 473 (2009) 51-87.

[58] K.S. Novoselov, Rev. Mod. Phys. 83 (2011) 837-849. 
Table 1. Composition of the stainless steel AISI 316L foam.

\begin{tabular}{|c|c|c|c|c|c|c|}
\hline & $\% \mathrm{Ni}$ & $\% C r$ & $\% M n$ & $\% F e$ & $\% M o$ & $\% C$ \\
\hline $\begin{array}{l}\text { Bulk (before rxn.), by } \\
\text { A.A. }\end{array}$ & 10.8 & 13.6 & 1.44 & 70.4 & n.d. & n.d. \\
\hline $\begin{array}{l}\text { Surface (after } \\
\left.\text { activation, }{ }^{* *}\right), \text { by } \\
\text { EDX }\end{array}$ & 5.3 & 10 & 1.2 & 76 & 0.7 & 1.56 \\
\hline
\end{tabular}

$\left(^{* *}\right)$ oxidation and reduction at $800^{\circ} \mathrm{C}$.

Table 2. Influence of oxidation temperature on the weight variations during activation, and on the carbon content after reaction ${ }^{(*)}$. Effect of oxidation temperature.

\begin{tabular}{ccccc}
\hline $\begin{array}{c}\text { Oxidation } \\
\text { Temp. }\left({ }^{\boldsymbol{O}} \boldsymbol{C}\right)\end{array}$ & $\begin{array}{c}\Delta \boldsymbol{W}_{\text {oxid }} / \boldsymbol{W}_{\boldsymbol{0}} \\
(\boldsymbol{\%})\end{array}$ & $\begin{array}{c}\Delta \boldsymbol{W}_{\text {reduc. }} / \boldsymbol{W}_{\boldsymbol{0}} \\
(\boldsymbol{\%})\end{array}$ & $\begin{array}{c}\Delta \boldsymbol{W}_{\text {reduc }} / \boldsymbol{W}_{\text {oxid. }} \\
(\boldsymbol{\%})\end{array}$ & $\begin{array}{c}\boldsymbol{C}_{\boldsymbol{C}} \\
\left(\mathbf{g} \boldsymbol{C} / \boldsymbol{W}_{\boldsymbol{0}}\right)\end{array}$ \\
\hline 700 & 2,2 & 1,2 & 56 & 0,40 \\
\hline 800 & 3,4 & 1,9 & 55 & 0,43 \\
\hline 900 & 4,9 & 2,3 & 46 & 0,72 \\
\hline
\end{tabular}

(*) $30 \mathrm{~min}$ of reaction at $800{ }^{\circ} \mathrm{C}$. Reduction and reaction temperature: $800{ }^{\circ} \mathrm{C}$, flowrate: $600 \mathrm{Nml} / \mathrm{min}$; feed composition (\%vol): $1.67 \mathrm{H}_{2} / 33.3 \mathrm{C}_{2} \mathrm{H}_{6} / 65 \mathrm{~N}_{2}$.

Table 3. Influence of reduction temperature on the weight variations during activation, and on the carbon content after reaction. Effect of reduction temperature.

\begin{tabular}{|c|c|c|c|c|}
\hline $\begin{array}{l}\text { Reduction } \\
\text { Temp. }\left({ }^{\circ} \mathrm{C}\right)\end{array}$ & $\begin{array}{c}\Delta W_{\text {oxid. }} / W_{0} \\
(\%)\end{array}$ & $\begin{array}{c}\Delta W_{\text {reduc. }} / W_{0} \\
(\%)\end{array}$ & $\begin{array}{c}\Delta W_{\text {reduc. }} / W_{\text {oxid. }} \\
\text { (\%) }\end{array}$ & $\begin{array}{c}C_{C} \\
\left(g C / W_{0}\right)\end{array}$ \\
\hline 700 & 2,9 & 1,4 & 48 & 0,39 \\
\hline 800 & 2,9 & 1,9 & 64 & 0,53 \\
\hline 850 & 2,7 & 1,3 & 49 & 0,36 \\
\hline 900 & 2,9 & 1,0 & 37 & 0,33 \\
\hline
\end{tabular}

(*) $30 \mathrm{~min}$ of reaction at $800{ }^{\circ} \mathrm{C}$. Oxidation and reaction temperature: $800{ }^{\circ} \mathrm{C}$, flowrate: $600 \mathrm{Nml} / \mathrm{min}$; feed composition (\%vol): $1.67 \mathrm{H}_{2} / 33.3 \mathrm{C}_{2} \mathrm{H}_{6} / 65 \mathrm{~N}_{2}$. 


\section{Figure Captions}

Figure 1. Sample weight evolution along the stages of a typical CCVD experiment.

Figure 2. SEM images of the foam: (a) fresh; (b,c) after oxidation at $800{ }^{\circ} \mathrm{C}$; (d) after reduction at $800{ }^{\circ} \mathrm{C}$

Figure 3. XRD patterns of the sample: (a) fresh foam; (b) after oxidation at $800{ }^{\circ} \mathrm{C}$; (c) after reduction at $800^{\circ} \mathrm{C}$; (d) after reaction at $800^{\circ} \mathrm{C}$.

Figure 4. SEM micrograph and Energy dispersive X-ray spectrum of the foam surface after oxidation and reduction at $800^{\circ} \mathrm{C}$.

Figure 5. Influence of oxidation temperature on the evolution carbon content.

Reduction and reaction temperature: $800^{\circ} \mathrm{C}$, flowrate: $600 \mathrm{Nml} / \mathrm{min}$; feed composition (\%vol): $1.67 \mathrm{H}_{2} / 33.3 \mathrm{C}_{2} \mathrm{H}_{6} / 65 \mathrm{~N}_{2}$.

Figure 6. SEM images of the foam after reaction at $800^{\circ} \mathrm{C}$ : $(\mathrm{a}, \mathrm{b})$ oxidation at $800^{\circ} \mathrm{C}$; (c,d) oxidation at $900^{\circ} \mathrm{C}$.

Figure 7. TEM images of the foam after reaction at $800^{\circ} \mathrm{C}$ : $(\mathrm{a}, \mathrm{b})$ oxidation at $800^{\circ} \mathrm{C}$; $(\mathrm{c}, \mathrm{d})$ oxidation at $900^{\circ} \mathrm{C}$.

Figure 8. TEM images after reaction at $800^{\circ} \mathrm{C}$, of the foam oxidized at $900{ }^{\circ} \mathrm{C}$.

Figure 9. Raman spectra after reaction at $800{ }^{\circ} \mathrm{C}$, of the foam oxidized at $800^{\circ} \mathrm{C}$.

Figure 10. Raman spectra after reaction at $800{ }^{\circ} \mathrm{C}$, of the foam oxidized at $900{ }^{\circ} \mathrm{C}$.

Figure 11. Influence of reduction temperature on the evolution carbon content. Oxidation and reaction temperature: $800{ }^{\circ} \mathrm{C}$, flowrate: $600 \mathrm{Nml} / \mathrm{min}$; feed composition (\%vol): $1.67 \mathrm{H}_{2} / 33.3 \mathrm{C}_{2} \mathrm{H}_{6} / 65 \mathrm{~N}_{2}$.

Figure 12. Raman spectra after reaction at $800^{\circ} \mathrm{C}$ of the foam reduced at $900^{\circ} \mathrm{C}$. 


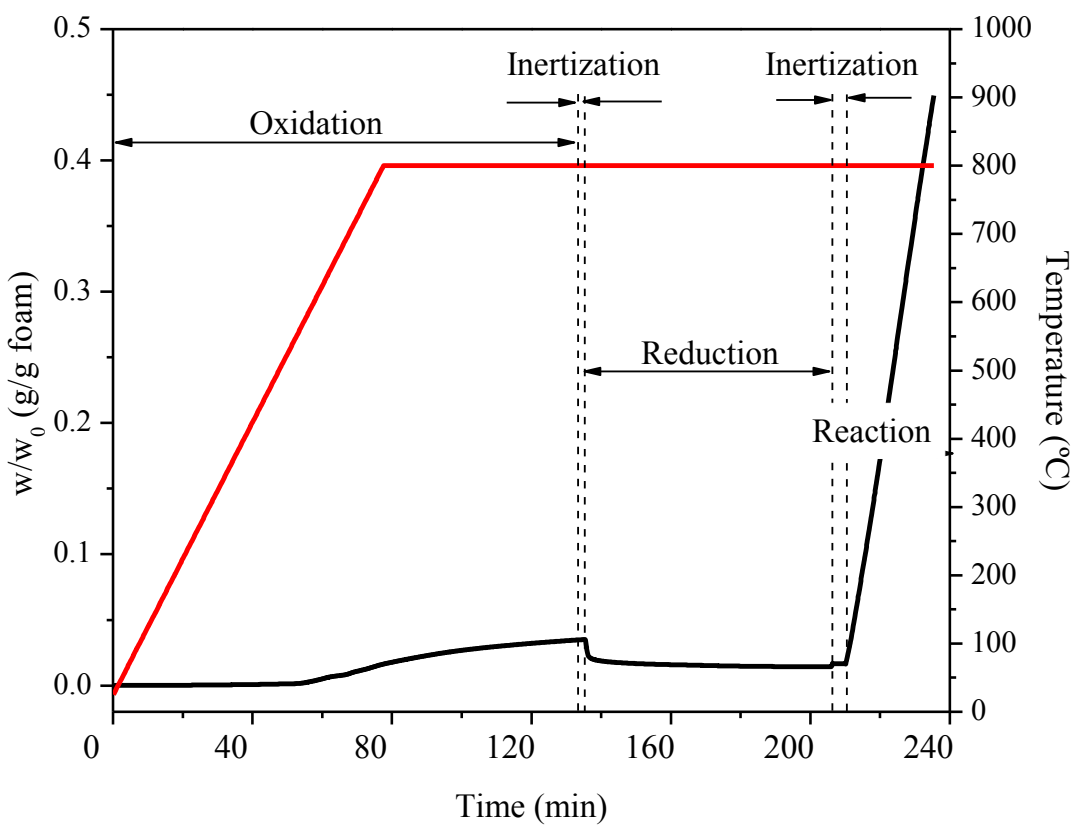

Figure 1. Evolution of weight along the stages of a typical CCVD experiment.

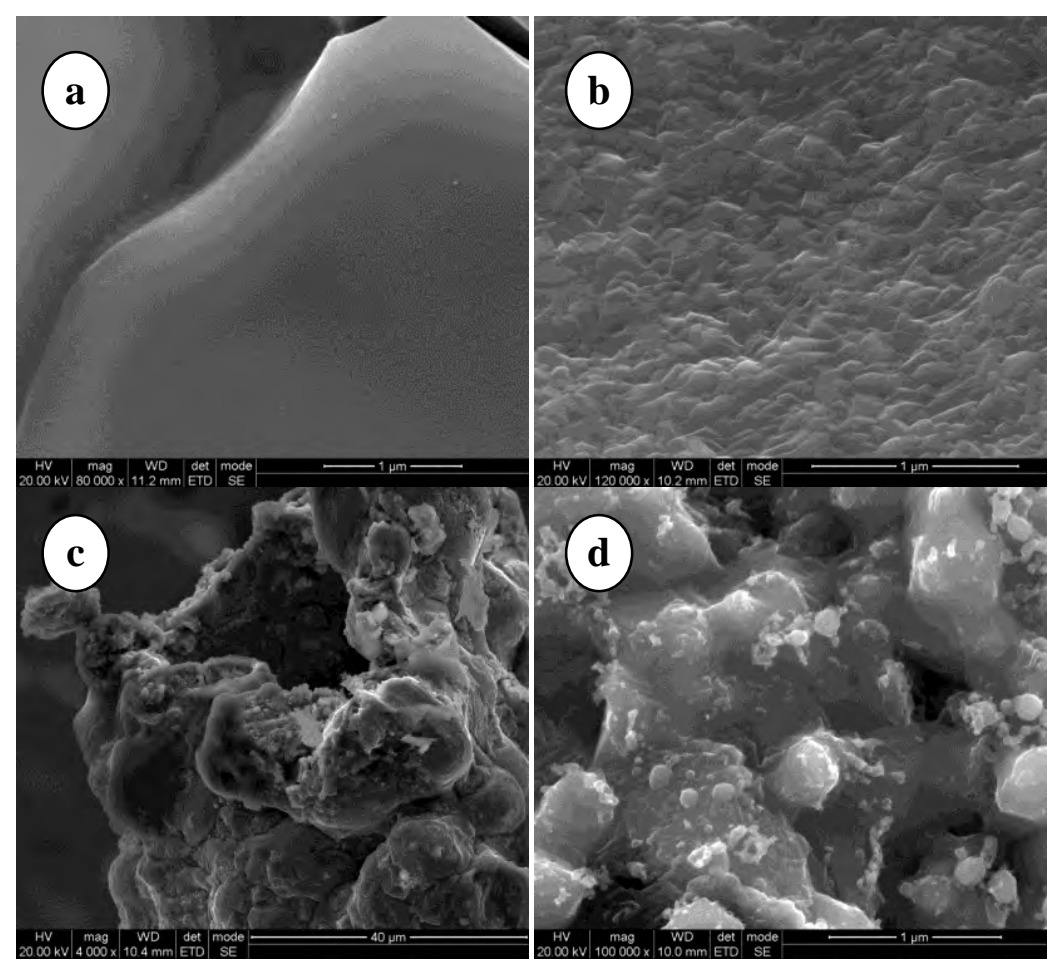

Figure 2. SEM images of the foam: (a) fresh; (b,c) after oxidation at $800{ }^{\circ} \mathrm{C}$; (d) after reduction at $800^{\circ} \mathrm{C}$. 


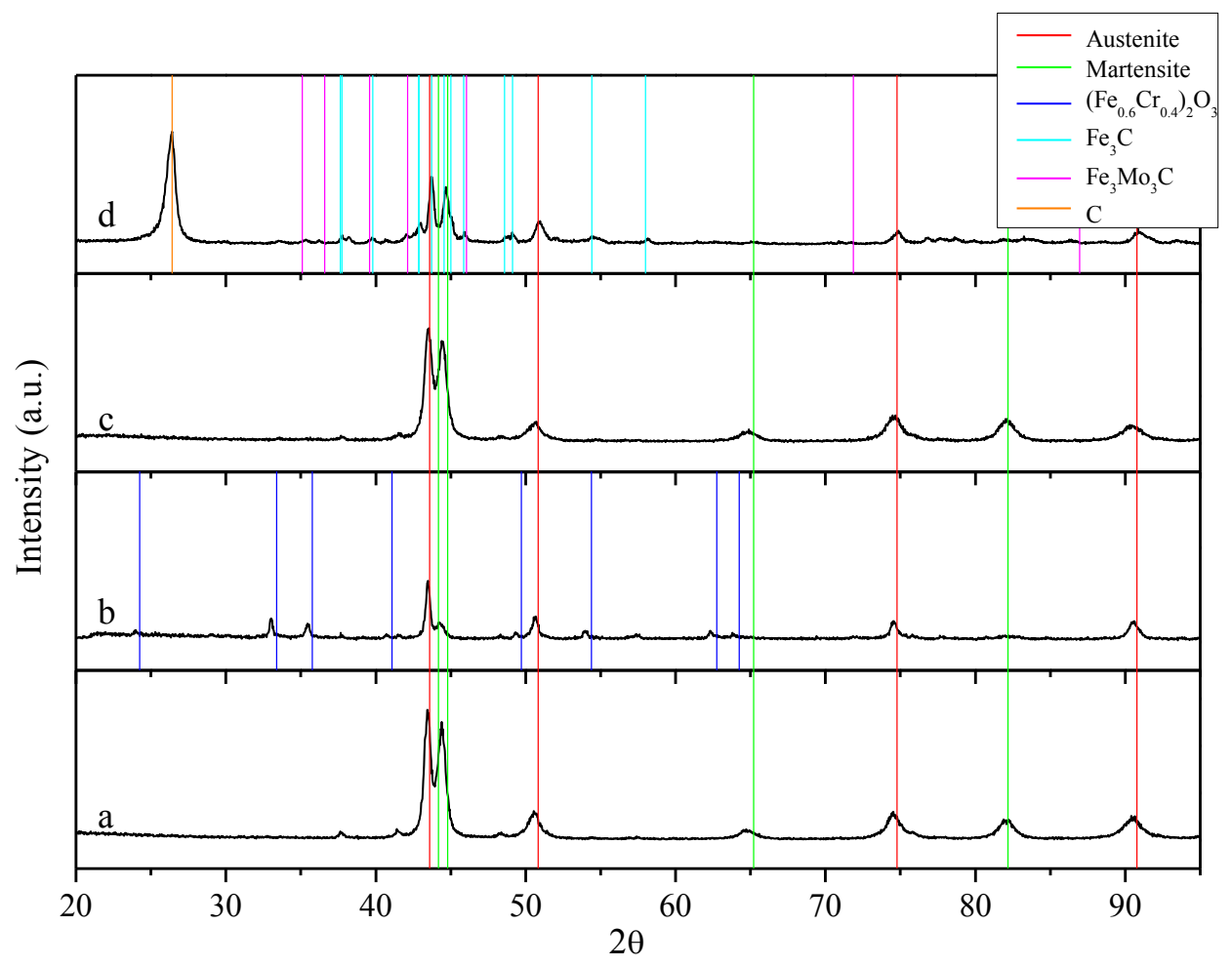

Figure 3. XRD patterns of the sample: (a) fresh foam; (b) after oxidation at $800{ }^{\circ} \mathrm{C}$; (c) after reduction at $800{ }^{\circ} \mathrm{C}$; (d) after reaction at $800^{\circ} \mathrm{C}$.

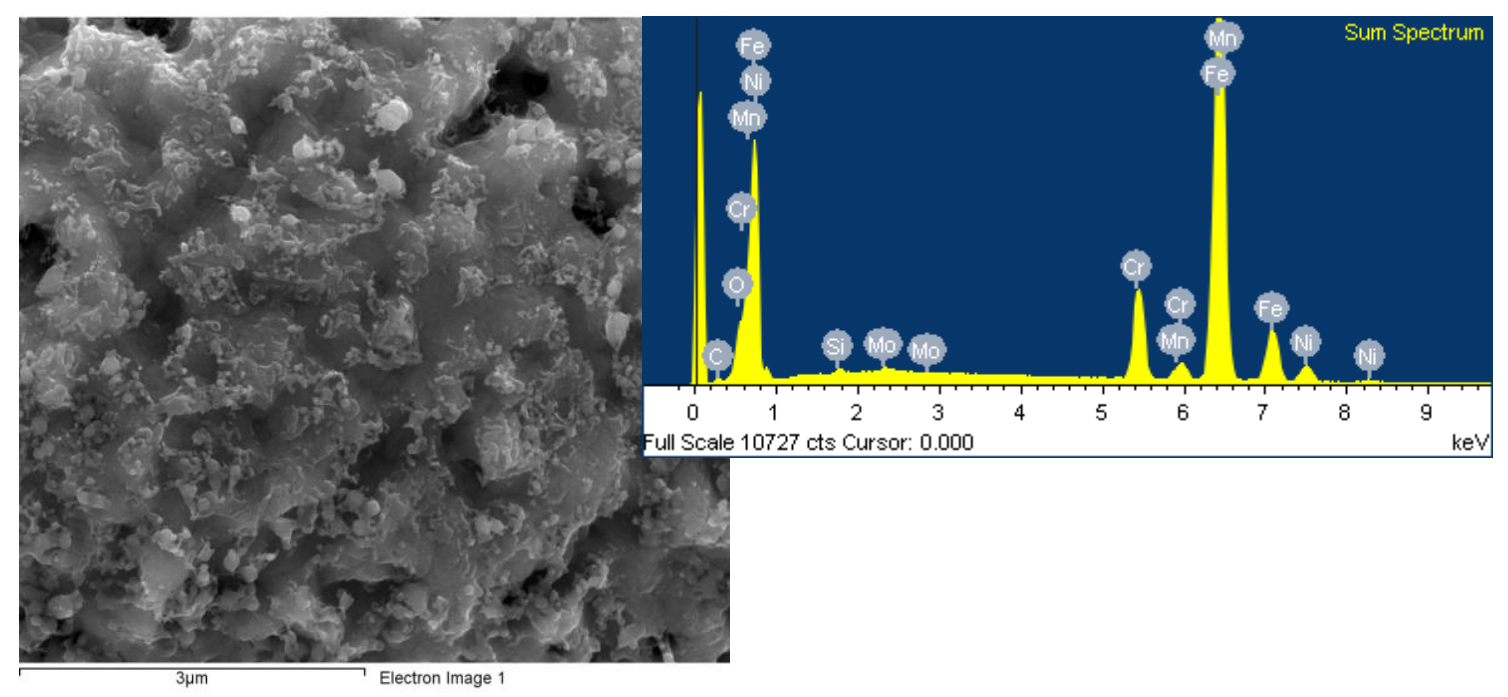

Figure 4. SEM micrograph and Energy dispersive X-ray spectrum of the foam surface after oxidation and reduction at $800^{\circ} \mathrm{C}$. 


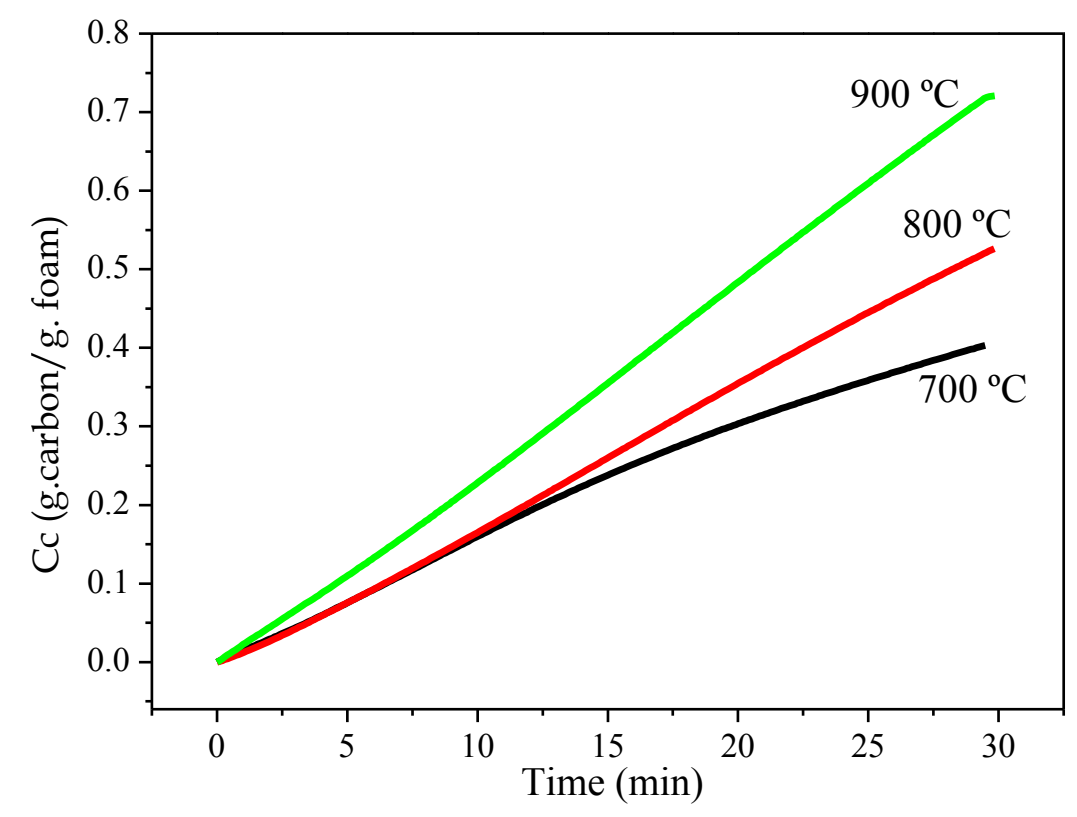

Figure 5. Influence of oxidation temperature on the evolution carbon content. Reduction and reaction temperature: $800{ }^{\circ} \mathrm{C}$, flowrate: $600 \mathrm{Nml} / \mathrm{min}$; feed composition(\%vol): $1.67 \mathrm{H}_{2} / 33.3 \mathrm{C}_{2} \mathrm{H}_{6} / 65 \mathrm{~N}_{2}$.

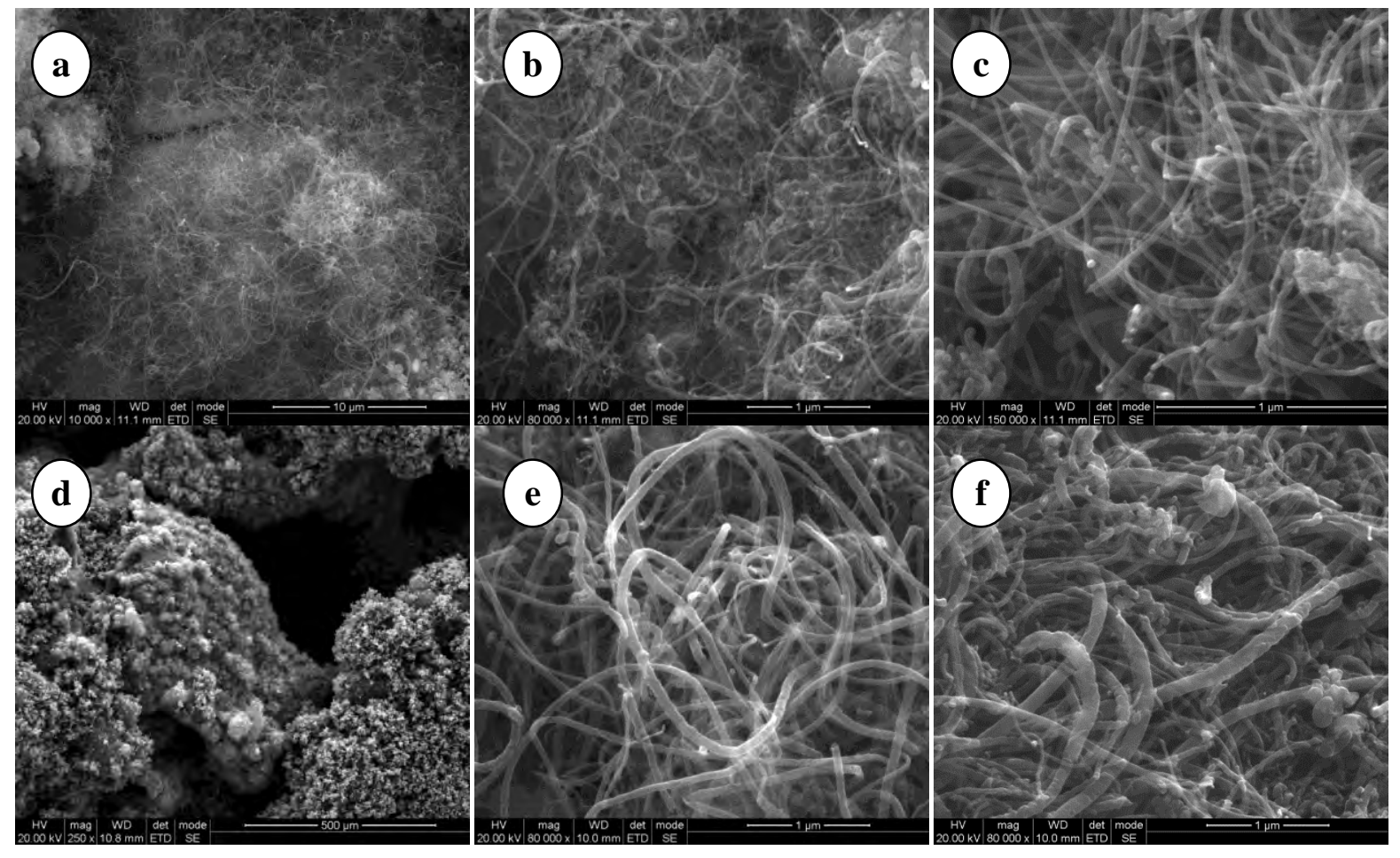

Figure 6. SEM images of the foam after reaction at $800^{\circ} \mathrm{C}:(\mathrm{a}, \mathrm{b}, \mathrm{c})$ oxidation at $800^{\circ} \mathrm{C}$; $(\mathrm{d}, \mathrm{e}, \mathrm{f})$ oxidation at $900^{\circ} \mathrm{C}$. 


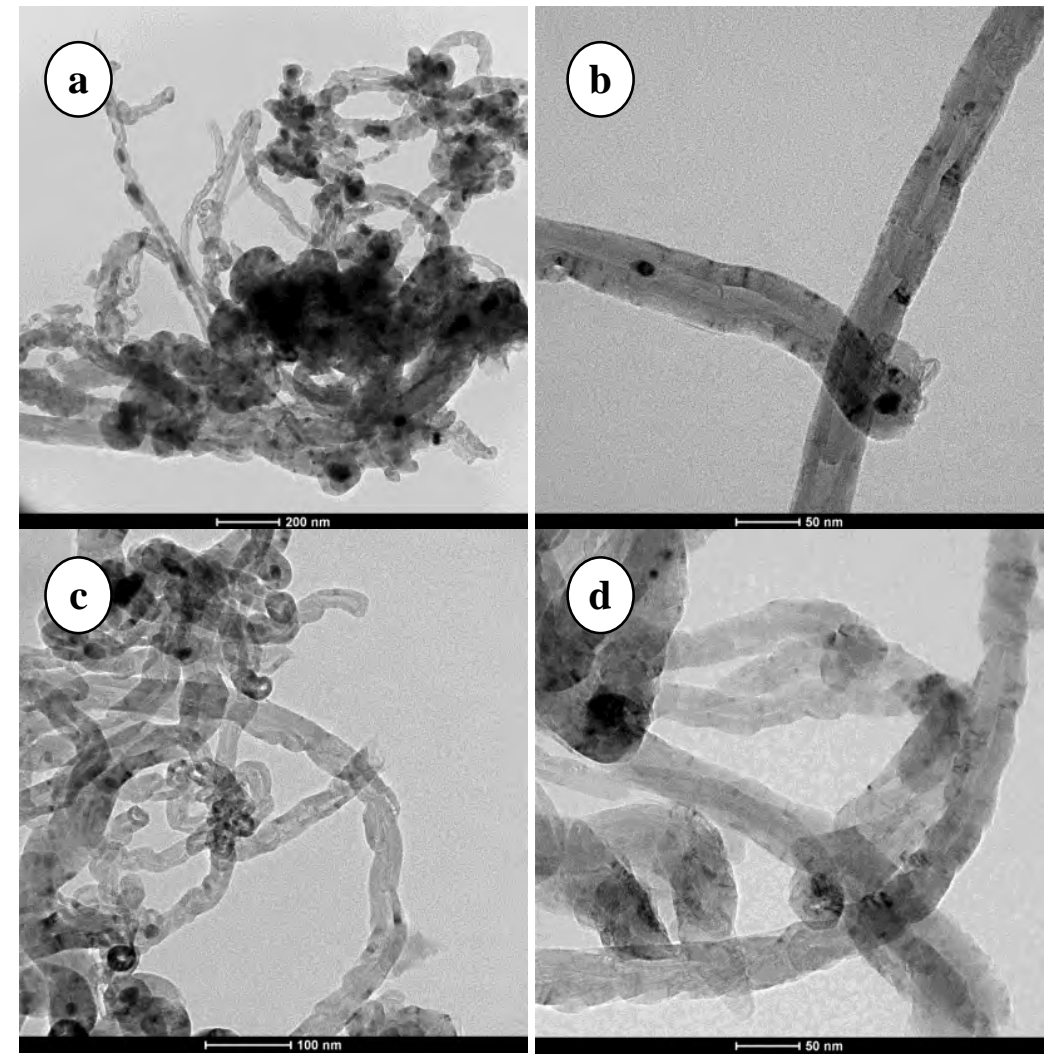

Figure 7. TEM images of the foam after reaction at $800^{\circ} \mathrm{C}$ : $(\mathrm{a}, \mathrm{b})$ oxidation at $800^{\circ} \mathrm{C}$; (c,d) oxidation at $900^{\circ} \mathrm{C}$.



Figure 8: TEM images after reaction at $800{ }^{\circ} \mathrm{C}$ of the foam oxidized at $900{ }^{\circ} \mathrm{C}$. 


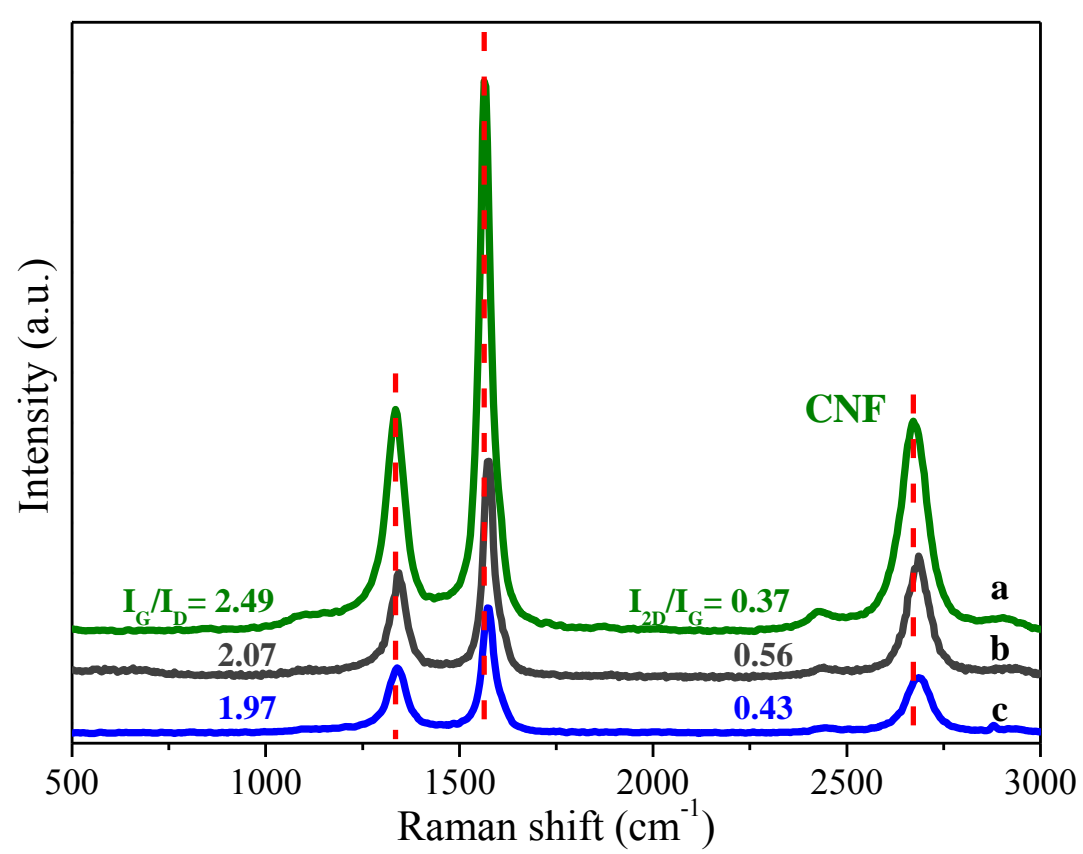

Figure 9. Raman spectra after reaction at $800^{\circ} \mathrm{C}$ of the foam oxidized at $800^{\circ} \mathrm{C}$.



Figure 10. Raman spectra after reaction at $800^{\circ} \mathrm{C}$ of the foam oxidized at $900^{\circ} \mathrm{C}$. 




Figure 11. Influence of reduction temperature on the evolution carbon content. Oxidation and reaction temperature: $800{ }^{\circ} \mathrm{C}$, flowrate: $600 \mathrm{Nml} / \mathrm{min}$; feed composition (\%vol): $1.67 \mathrm{H}_{2} / 33.3 \mathrm{C}_{2} \mathrm{H}_{6} / 65 \mathrm{~N}_{2}$.

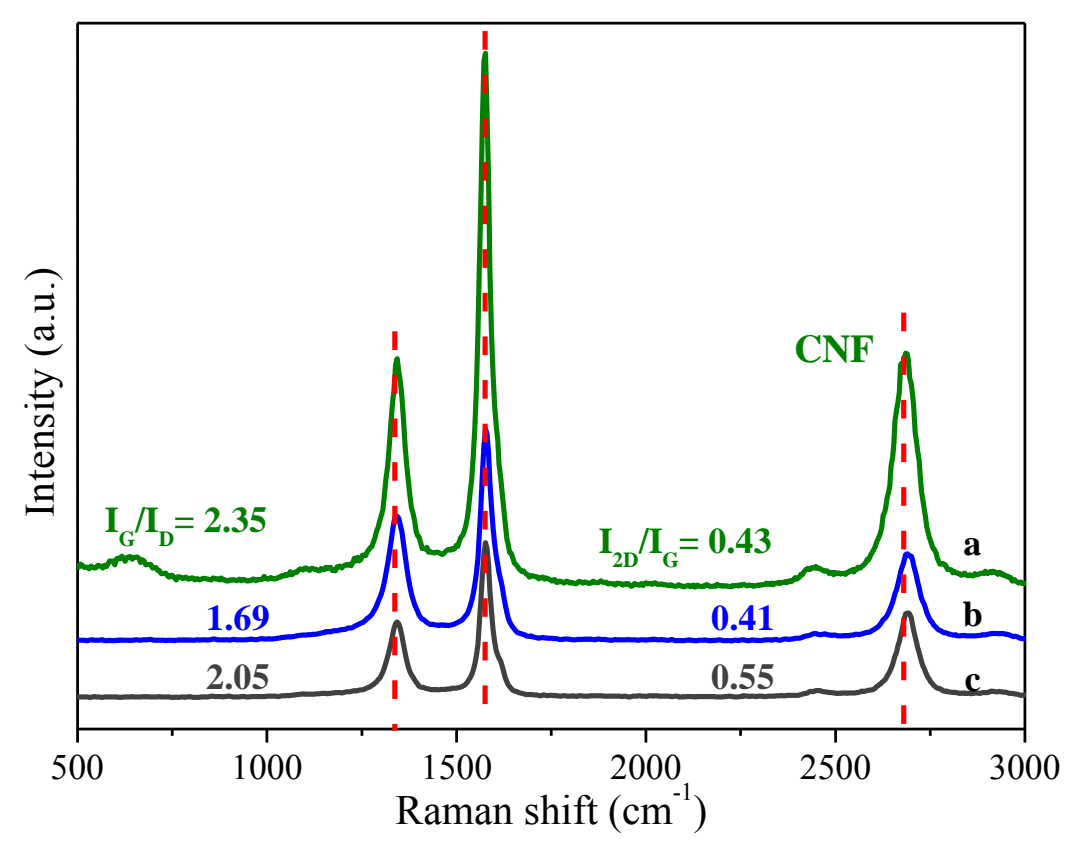

Figure 12. Raman spectra after reaction at $800^{\circ} \mathrm{C}$ of the foam reduced at $900^{\circ} \mathrm{C}$. 